\title{
Fetal Cortical Transplants in Adult Rats Subjected to Experimental Brain Injury
}

\author{
Holly Soares and Tracy K. McIntosh \\ CNS Injury Laboratory, Surgical Research Center \\ Department of Surgery \\ University of Connecticut Health Center \\ Farmington, CT 06032, U.S.A.
}

\section{SUMMARY}

Fetal cortical tissue was injected into injured adult rat brains following concussive fluid percussion (FP) brain injury. Rats subjected to moderate FP injury received E16 cortex transplant injections into lesioned motor cortex 2 days, 1 week, 2 weeks, and 4 weeks post injury. Histological assessment of transplant survival and integration was based upon Nissl staining, glial fibrillary acidic protein (GFAP) immunocytochemistry, and staining for acetylcholinesterase. In addition to histological analysis, the ability of the transplants to attenuate neurological motor deficits associated with concussive FP brain injury was also tested. Three subgroups of rats receiving transplant 1 week, 2 weeks, and 4 weeks post injury were chosen for evaluation of neurological motor function. Fetal cortical tissue injected into the injury site 4 weeks post injury failed to incorporate with injured host brain, did not affect glial scar formation, and exhibited extensive GFAP immunoreactivity. No improvement in neurological motor function was observed in animals receiving transplants 4 weeks post injury. Conversely, transplants injected 2 days, 1 week, or 2 weeks post injury survived, incorporated with host brain, exhibited little GFAP immunoreactivity, and successfully

\footnotetext{
Reprint address:

Tracy K. McIntosh

CNS Injury Lab., Surgical Research Center

Department of Surgery

University of Connecticut Health Center

Farmington, CT 06030, U.S.A.
}

attenuated glial scarring. However, no significant improvement in motor function was observed at the one week or two week time points. The inability of the transplants to attenuate motor function may indicate inappropriate host/transplant interaction. Our results demonstrate that there exists a temporal window in which fetal cortical transplants can attenuate glial scarring as well as be successfully incorporated into host brains following FP injury.

Key words: Nerve regeneration; brain injury; neural transplantation.

\section{INTRODUCTION}

The precise pathological sequelae following traumatic brain injury remains largely uncharacterized. However, prominent vascular disruption and alterations of blood-brain barrier function have frequently been reported during the acute phase of trauma in both clinical and experimental brain injury $/ 12-14,47,50,62 /$. It is known that early vascular and metabolic damage resulting from trauma are often associated with secondary or delayed pathological events including neuronal loss, lymphocytic infiltration, glial proliferation, and scar formation $/ 1,4,20,30,47 /$. In our model of lateral fluid percussion (FP) brain injury, traumatic damage takes place over a period of weeks. Previous work has demonstrated that 
by two to four weeks post injury, a cavity within lesioned parietal motor cortex forms, surrounded by a glia limitans /12/. Delayed secondary hippocampal and thalamic neuronal losses also occur /12/. In addition, the cavity size, the extent of neuronal histopathological damage, and the subsequent neurologic motor dysfunction all relate directly to the severity of the injury $/ 12,42 /$.

Acute administration of novel pharmacological agents has been used to antagonize the pathophysiological sequelae following traumatic brain injury. Virtually no studies have attempted to utilize fetal transplants as a replacement for neuronal losses that follow concussive brain injury, and nothing is known about the ability of fetal cortical transplants to survive, integrate, and affect motor outcome in host brains subjected to FP brain injury. However, much work has been done characterizing fetal cortical transplants in both lesioned newborn cortex $/ 9,10,17 /$ as well as lesioned adult cortex $/ 6,22,54 /$. In models using scoop or penetrating lesions, transplant survival may be influenced by the injury-mediated release of trophic factors $/ 22,41,43-45 /$. In addition, the immunological responses of host/transplant interactions may play a key role in transplant survival and integration $/ 2,32,38,39 /$. Fetal cortical transplants which survive in lesioned brain are capable of receiving afferent and efferent projections to both appropriate and inappropriate targets $/ 18,23,24,29,54 /$. Surviving fetal cortical transplants may also exert trophic influences upon host tissue /7,24-26,55,57/. However, there have been mixed reports describing the ability of fetal transplants to function normally and/or display appropriate morphological characteristics $/ 9,10,15,17,19,29,53,56 /$.

Unlike scoop lesions or penetrating lesions, FP traumatic brain injury leaves the dura intact. Brain trauma also often involves complicating secondary factors including hypoxia, brain edema, lymphocytic infiltration, decreases in cerebral blood flow, delayed neuronal loss in brain regions adjacent to the primary lesion, and protracted scar formation $/ 12,42,47,50,62,65,66 /$. Although studies examining trophic factor release report transplant survival to be maximal when the fetal tissue is transplanted one to two weeks after scoop or stab lesion $/ 23,43-45 /$, it is unclear whether a similar timecourse for optimal transplant survival exists in our model of brain injury. Furthermore, cavity formation and scarring may also influence transplant viability. The present clinically relevant study examines the ability of fetal cortical transplants to survive within the changing pathological milieu of traumatized brain and whether such transplants can affect post-traumatic neurological motor dysfunction.

\section{MATERIALS AND METHODS}

\section{Animal surgery}

Sprague-Dawley male rats $(350-450 \mathrm{~g})$ were anesthetized with $60 \mathrm{mg} / \mathrm{kg}$ sodium pentobarbital i.p. A midline incision was made in the scałp skin and left temporal muscles were retracted. All incisions were injected with $1 \%$ lidocaine hydrochloride. A $5.0 \mathrm{~mm}$ craniotomy was made over the left parietal cortex midway between bregma and lambda. A Luer-Lock fitting was super-glued into the craniotomy and the entire apparatus was dental cemented securely to the skull. Ninety minutes following the initial sodium pentobarbital injection, anesthetized animals were subjected to moderate FP brain injury (2.3 $2.4 \mathrm{~atm}$.) as previously described /42/. This brain injury model uses a rapid injection of a saline pressure pulse into the cranial cavity to produce a transient deformation of the brain.

\section{Fetal tissue dissection}

Female timed pregnant albino SpragueDawley rats (200-250 g) were anesthetized with $50 \mathrm{mg} / \mathrm{kg}$ sodium pentobarbital i.p. on embryonic day 16 (E16). E16 fetuses were removed individually by Cesarian section. All dissections were performed under a Reichert stereozoom microscope and with tissue submerged in sterile lactated Ringer's at room temperature during dissections. Scalp and dura were removed with \#3 fine microforceps. \#5 microforceps were utilized to pick off remaining meninges from parietal cortical surfaces. Left parietal cortex was separated from brain and Vannas scissors were used to cut a $3 \times 3 \mathrm{~mm}$ square of left parietal cortex (approximate volume $3-5 \mu$ l). 3 $\mu l$ of whole tissue was suctioned gently into the glass capillary needle and injected immediately into prepared brain-injured animals. 


\section{Fetal tissue transplantation}

Sixty host animals received $3 \mu$ injections of either whole tissue E16 fetal parietal cortical tissue or sterile lactated Ringer's into injured parietal/temporal cortex at two days $(n=6)$, one week $(n=18)$, two weeks $(n=20)$, or four weeks $(n=16)$ post injury. On the day of transplantation, animals were anesthetized with $55 \mathrm{mg} / \mathrm{kg}$ sodium pentobarbital i.p. The skull was exposed by retracting the skin and left temporalis muscles. The maximal site of injury (including the site of the injury cavity) was chosen as the primary area for fetal cell transplantation. Stereotaxic coordinates of the lesion's location were based upon previous histological examinations /12/ (and unpublished observations). Stereotaxic coordinates were as follows /46/: AP $-2.3 \mathrm{~mm}$ through $-6.2 \mathrm{~mm}$ bregma, DV $-2.5 \mathrm{~mm}$ to $-4.5 \mathrm{~mm}$ from dura. A small hole was drilled through the temporalis bone (AP -4.0 bregma and DV $-3.5 \mathrm{~mm}$ ) over the center of the lesion. A $20 \mu$ l capillary tube (o.d. $0.300 \mathrm{~mm}$ ) was utilized as an injection needle. The sterilized glass needle was positioned stereotaxically through the drilled craniotomy inserted $1 \mathrm{~mm}$ from dura into the injury cavity. Fetal cells were injected slowly into the injury site and the capillary needle was gradually withdrawn. The craniotomy was closed with bone wax.

\section{Neurologic evaluation}

Previous studies have suggested that maximal survival of cortical transplants occurs when the grafts are transplanted 1 to 2 weeks post injury following cortical scoop lesions $/ 23,43 /$. Therefore, animals receiving fetal transplant injections at one week, two weeks, and four weeks post injury were chosen for neurological tests. Chronic post-injury motor function was assessed in all animals at 24 hours and once each week after brain injury until the day of transplantation using previously described paradigms $/ 14,41 /$. Animals were scored from 4 (normal) to zero (severely impaired) for each of the following indices: (1) contralateral forelimb flexion response on suspension by the tail, (2) decreased resistance to lateral pulsion, (3) ability to stand on an inclined plane (angle board) that determined the greatest angle at which animals can maintain their position, and (4) movements across a grid field measured by a computerized activity monitor (Opto-Varimax, Columbus Instruments). The inclined plane consisted of a hinged wooden plane, covered with a rubber mat with $2 \mathrm{~mm}$ vertical ribs. The hinged plane was adjustable in two-degree increments. Animals were placed on the inclined plane to determine the maximum angle at which they could maintain their position, which was successively increased by two-degree increments between placements. The maximal baseline angle at which the animal could stand for 5 seconds in the vertical and horizontal positions were recorded prior to injury. Ranked scores following injuries were as follows: baseline angle $=4 ; 0.5^{\circ}-2.5^{\circ}$ less than baseline $=3 ; 2.75^{\circ}-5.0^{\circ}$ less than baseline $=3$; $5.5^{\circ}-7.5^{\circ}$ less than baseline $=2 ; 10^{\circ}$ or more below baseline $=0$. Spontaneous horizontal activity, both stereotypic and ambulatory, as well as vertical activity (i.e. ability to balance on hind limbs) was recorded for 5 minute sessions. Activity scores were calculated as percentages of baseline activity prior to injury; $89-100 \%=4$, 78$88 \%=3.5,67-77 \%=3,56-66 \%=2.5,45-55 \%$ $=2,34-44 \%=1.5,23-33 \%=1,12-22 \%=0.5$, and $0-11 \%=0$. A total composite functional neurologic score $(0-20)$ was obtained by combining the scores of left, right, and vertical angleboard, right contraflexion, and right lateral pulsions so that $20=$ normal, $15=$ slightly impaired, $10=$ moderately impaired, $5=$ severely impaired, and $0=$ nonfunctional. Activity monitor scores were analyzed separately.

\section{Histological analysis}

Animals receiving injections were allowed to survive for four weeks following the transplant injection into the injury cavity. Animals were then anesthetized with $60 \mathrm{mg} / \mathrm{kg}$ sodium pentobarbital i.p. and perfused through the ascending aorta with $100 \mathrm{ml}$ heparinized saline followed by 4\% paraformaldehyde. Brains were removed and stored for an additional 2 hours in perfusate then transferred to $0.1 \mathrm{M}$ phosphate buffer $\mathrm{pH}$ 7.4 and stored at $4^{\circ} \mathrm{C}$. Alternating $50 \mu \mathrm{m}$ Vibratome (Pelco) sections were Nissl-stained with toluidine blue, stained for acetylcholinesterase (AchE) utilizing AchE-modified methodology $/ 61 /$, or immunoreacted for glial fibrillary acidic protein (GFAP). Sections stained 
for GFAP immunocytochemistry were free floated in the following manner: (1) 30 minutes in $3 \% \mathrm{H}_{2} \mathrm{O}_{2}$ followed by 2 five-minute rinses in $0.05 \mathrm{M}$ Tris- $\mathrm{HCl}$ buffer, $\mathrm{pH} 7.6$; (2) 1 hour in 2\% normal goat serum, $0.05 \%$ pure BSA, and $0.1 \%$ Triton-X, all in Tris- $\mathrm{HCl}$ buffer; (3) overnight incubation with a 1:600 dilution of rabbit antiGFAP (Incstar) followed by 2 five-minute buffer rinses; (4) 1 hour in a 1:100 dilution of goat antirabbit IgG conjugated to horseradish peroxidase followed by 3 five-minute rinses, and (5) incubated in $0.04 \%$ 3-3' diaminobenzidine (DAB), $0.2 \%$ nickel ammonium sulfate, and $1 \%$ $\mathrm{H}_{2} \mathrm{O}_{2}$ until GFAP positive cells were observed (about 5-15 minutes). As an immunohistochemical control, alternating sections were incubated in the absence of the primary antibody. The sections were dehydrated, cleared in xylene, and cover-slipped.

The transplants were evaluated histologically using light microscopy. Criteria for successful transplants were as follows: (1) the ratio of neurons/glia was equal to or greater than one at either ventral, dorsal, or hippocampal interfaces (total 3 points); (2) there was no necrosis within the center of the transplant, and the ratio of neurons/glia was greater than one (total of 1 point); (3) there were no spaces along the ventral, dorsal, or hippocampal interface (total 3 points); (4) the grafts were vascularized at the ventral, dorsal, or hippocampal interface (total 3 points); (5) acetylcholinesterase positive fibers traversed ventral, dorsal, or hippocampal interfaces (total 3 points); (6) the transplant was correctly injected into the cavity (total 1 point), and (7) the absence of a GFAP reactive astrocytic scar at ventral, dorsal, or hippocampal interface (total 3 points). For each criterion satisfied, a nominal score of 1 was assigned; if the criterion was not satisfied a score of 0 was assigned. The total score for each section was 17 . Four sections from different rostral/caudal levels (one from -2.3 to $-3.3,-3.3$ to $-4.3,-4.3$ to -5.3 , and -5.3 to -6.3 bregma) were analyzed for each brain. The maximal histological cumulative score possible was 68 .

\section{Data analysis}

Ordinal neurological and histological
measurements were evaluated utilizing

nonparametric Kruskal-Wallis ANOVA followed by individual nonparametric Mann-Whitney $U$ tests. A $\mathrm{P}$ value of $<0.05$ was considered statistically significant. All data are shown as means \pm S.E.M.

\section{RESULTS}

Animals subjected to lateral FP injury exhibited consistent morphopathological changes. Previous studies have shown that in the acute stages post injury, blood vessels within the injured cortex are dilated and hemorrhage is prominent along the adjacent external capsule /12/. Reactive gliosis and lymphocytic infiltration also occur $/ 12 /$. By two to four weeks post injury, all of the cortical neurons are lost at the focus of the lesions and a cavity forms delineated by a glia limitans /12,42/. Neuronal losses are evident in hippocampal and thalamic regions; however, cavitation does not occur $/ 12,42 /$.

Figure 1 illustrates the effects of using fetal cell transplants within injured rat parietal cortex following FP injury. Transplants performed at two days post injury demonstrated a higher neuronal cell density than surrounding host cortex and this may indicate robust viability of the transplant. Preliminary results also showed neuronal sparing of $\mathrm{CA} 2 / \mathrm{CA} 3$ hippocampal regions within injured host brains receiving transplants two days post injury (Figure 1A,B). AchE-positive fibers were numerous and traversed the transplant/host interface in animals receiving transplants two days post injury (Figure 2A,2a). As a group, transplants injected two days post injury appeared well integrated with host tissue. They also showed little glial scarring or reactive astrocytosis when examined with GFAP immunocytochemistry (Fig. 2B,2b).

Transplants injected one or two weeks post injury also exhibited greater neuronal cell density than surrounding host cortex (Figure 1C,D; $1 \mathrm{E}, \mathrm{F})$. However, in these cases, sparing of CA2/CA3 hippocampal neurons was not apparent. The degree of viability of these transplants injected one week post injury was similar to that observed for transplants performed two days post injury. Large numbers of AchE-positive fibers spanned host/transplant interfaces 

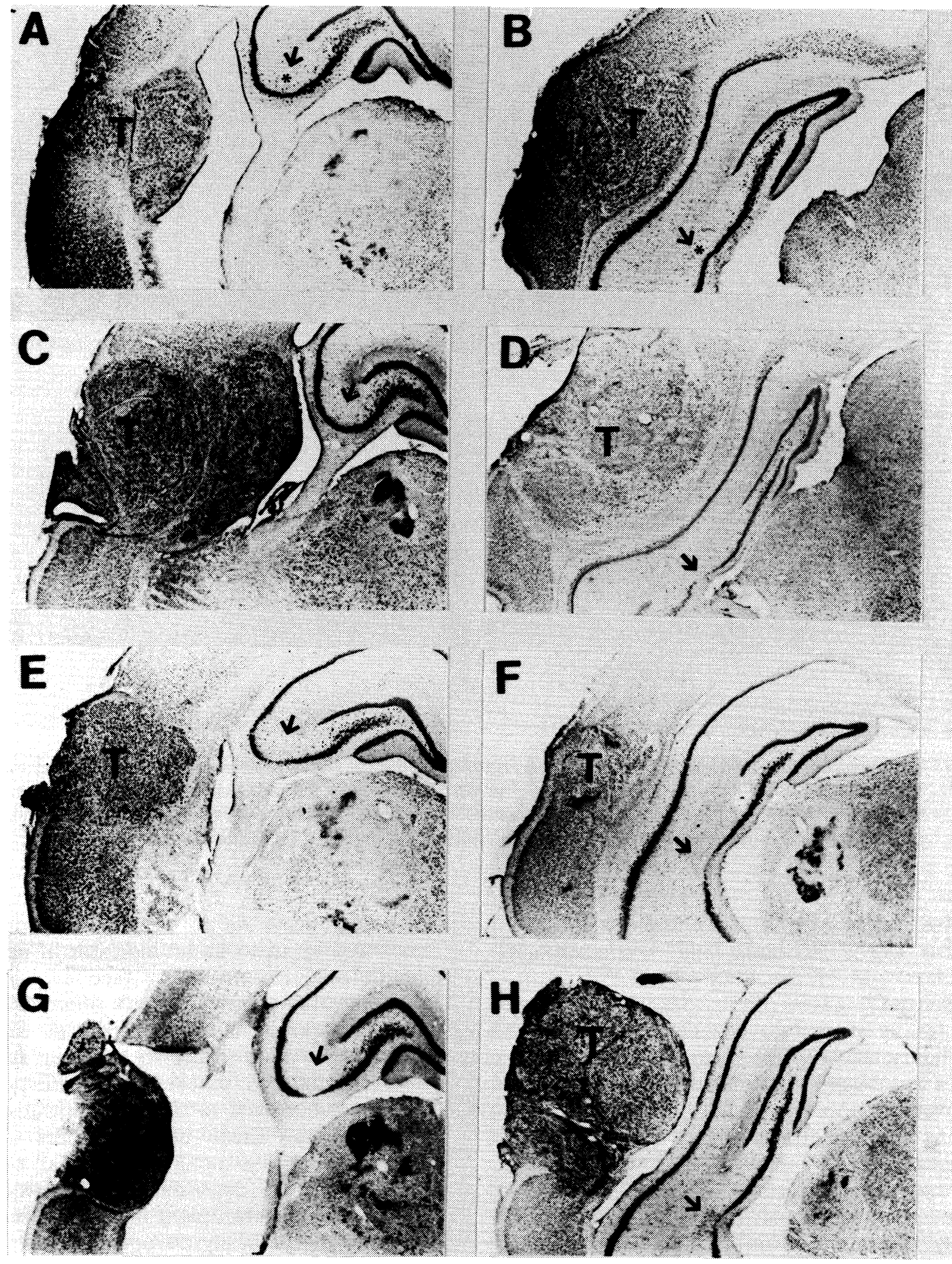

Fig. 1: Toluidine blue staining (16X) of E16 fetal transplants four weeks post transplant. Fetal cortical tissue was transplanted two days post injury $(A, B)$, one week post injury $(C, D)$, two weeks post injury $(E, F)$ and four weeks post injury $(\mathbf{G}, \mathbf{H})$. Arrows with asterisks indicate CA2/CA3 hippocampal sparing. Arrows indicate CA2/CA3 hippocampal neuronal loss. 

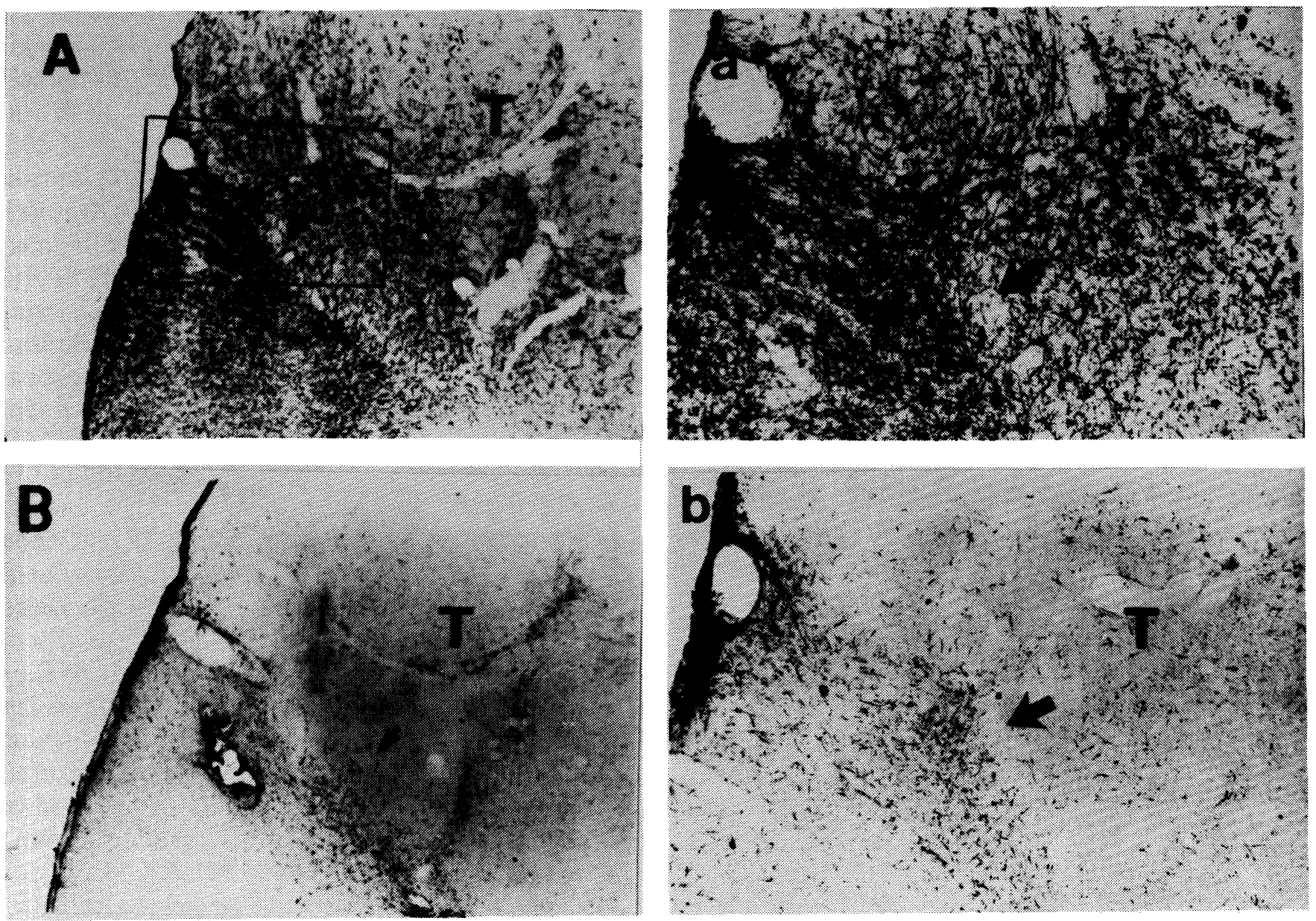

Fig. 2: E16 fetal cortical transplant, $T$, injected two days post-injury. (A) Acetylcholinesterase staining (40X) of the ventral host/donor cortical interface. The arrows indicate the cortical interface region. (a) 100X magnification of the boxed region in (A). (B) GFAP immunocytochemistry (40X) of a transplant injected two days post-injury. (b) GFAP staining of an adjacent section depicted in (a) at $100 \mathrm{X}$.

(Figures 3A,3a; 4A,4a), and there were few reactive astrocytes along the host/transplant interfaces or throughout the transplants themselves (Figures 3B,3b; 4B,4b). Although viable grafts were observed as late as two weeks post injury, the success rate of the two week groups was much less than that of the two day or one week group. In addition, traces of glial scarring were sometimes evident in the two week group.

Transplants performed 4 weeks post injury showed no evidence of increased neuronal cell density within the transplant and there were numerous macrophages present (Figure 1G,H). GFAP positive astrocytes were also abundant throughout the transplant especially where the transplant interfaced with host tissue (Figure
5B,5b). Extensive GFAP immunoreactivity was considered by us to be an indicator of necrosis and transplant nonviability (see Discussion). Frequently, the transplants were separated from the host tissue by a pronounced glial capsule. Fibers often ran parallel to the scar surface. However, narrow patches of AchE-positive fibers were observed to traverse the transplant/ host interface. These bridging fibers usually occurred primarily along the ventral cortical interface. Their consistent ventral location suggests that the transplant injection procedure may have mechanically disrupted the astrocytic scar creating an opening for these fibers to pass. Unlike earlier time points, AchE-positive fibers rarely traversed the host/transplant interfaces and were scarce within the transplant itself 


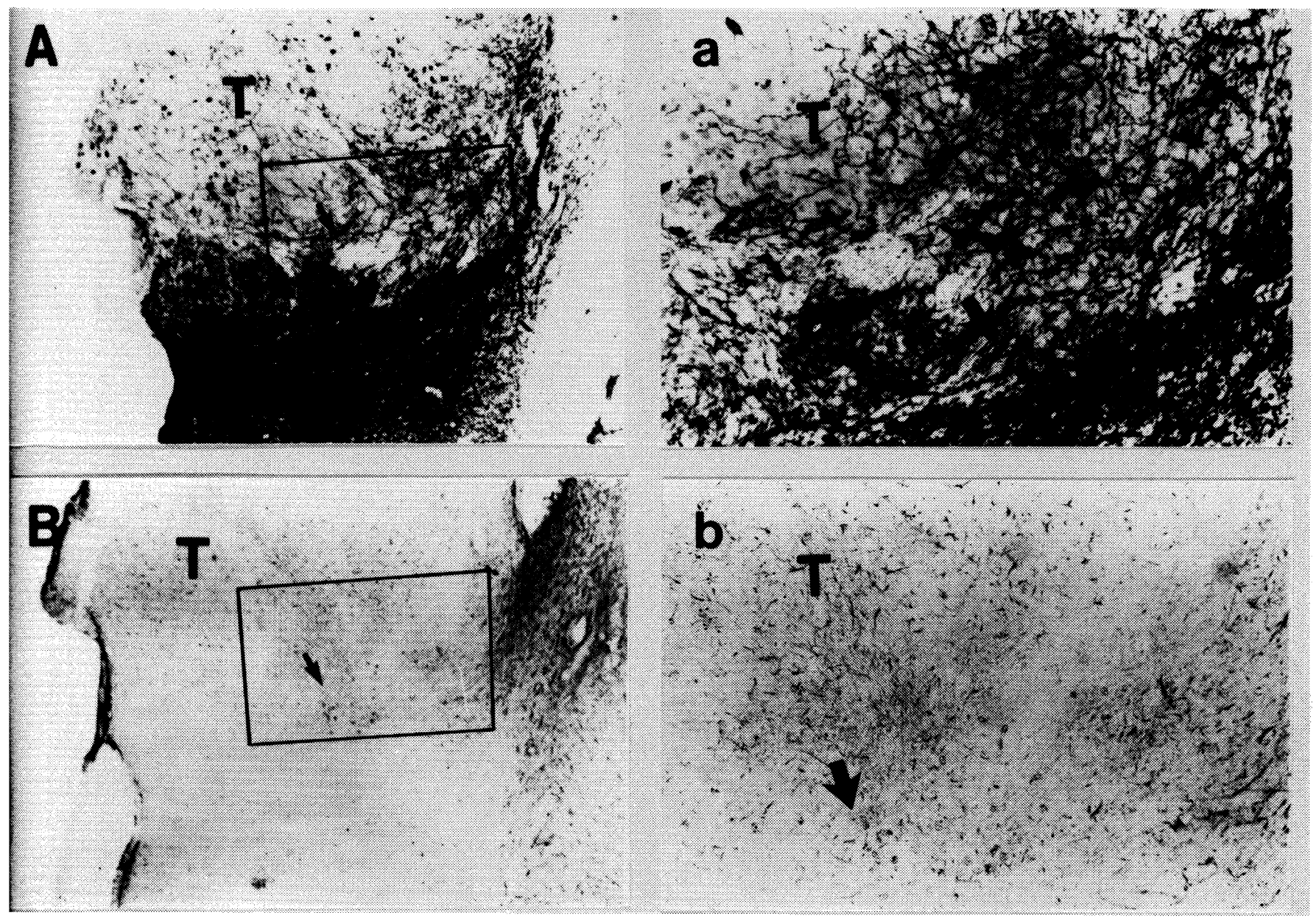

Fig. 3: E16 fetal cortical transplant, T, injected one week post injury. (A) acetylcholinesterase staining (40X) of the ventral host/donor cortical interface. The arrows indicate the cortical interface region. (a) 100X magnification of the boxed region in (A). (B) GFAP immunocytochemistry (40X) of a transplant injected one week post injury. (b) GFAP staining of the boxed region in (B) at 100X.

(Figure 5A,5a). This was consistent with the general observation that regions of the interface containing numerous reactive glia usually had few penetrating AchE fibers and vice versa (compare Figures 2,3,4,5). By the above criteria, none of the 8 cases which received transplants 4 weeks post injury were considered to be successfully incorporated into the host tissue at the time of sacrifice (4 weeks following transplantation).

Figure 6 summarizes the cumulative histology scores used to evaluate transplant viability. In general, transplants injected two days and one week following brain injury incorporated into the host brain most successfully. These transplants had above normal cell density, very little necrosis, few reactive glia, and well-integrated host/donor interfaces. There were fewer AchE- positive fibers throughout the transplant than in the surrounding host tissue, but this was a general feature of all the groups in our study. Transplants injected two weeks after injury exhibited a high degree of variability and on average were intermediate in viability. Transplants injected four weeks post injury were poorly incorporated and considered unsuccessful.

Table 1 illustrates composite neurological scores of animals receiving transplants of fetal cortex compared to animals receiving injections of sterile lactated Ringer's. Animals injected with fetal tissue two and four weeks post injury tended to perform worse on neurological motor tasks when compared to controls injected with Ringer's two and four weeks post injury. Rats 

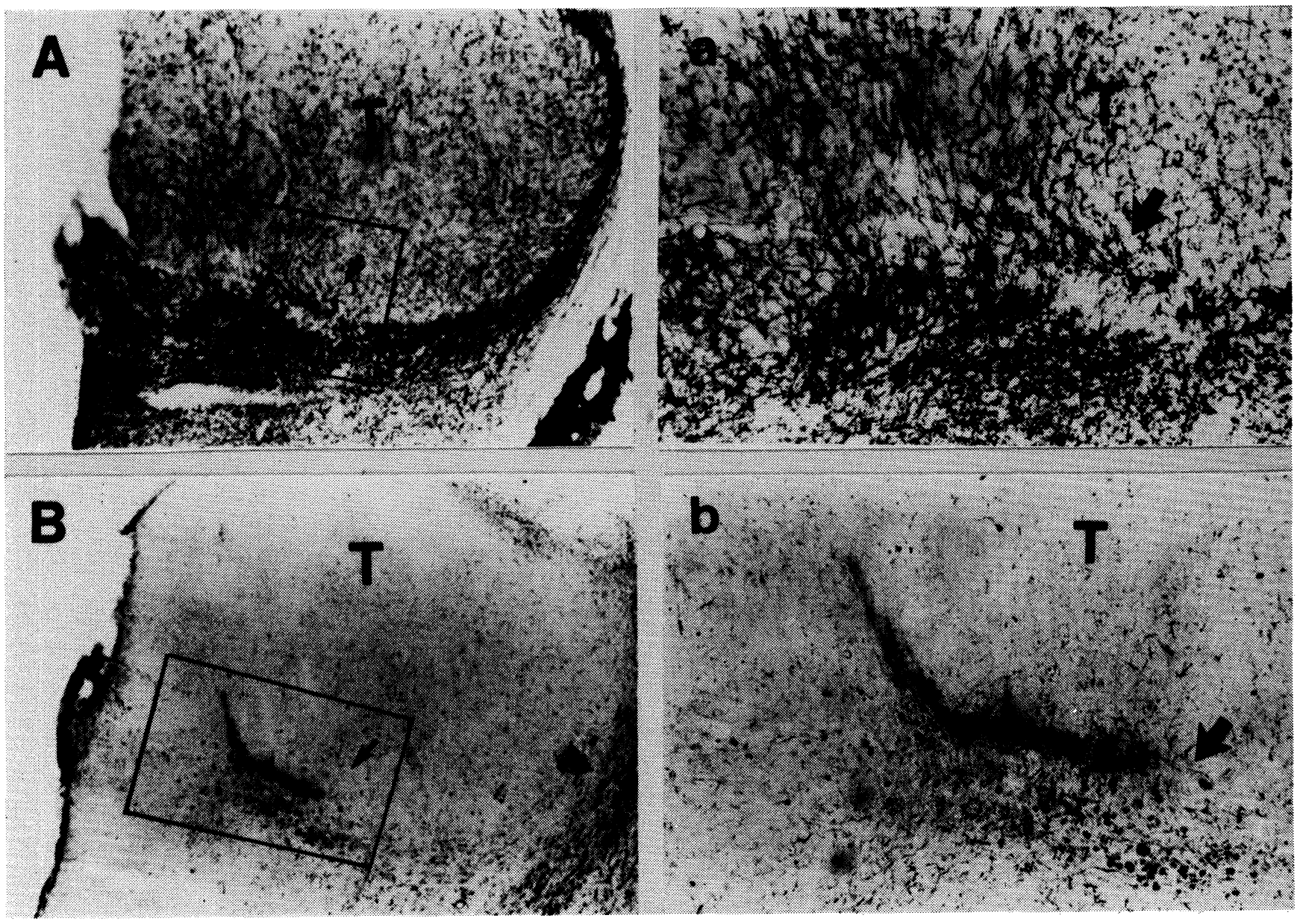

Fig. 4: E16 fetal cortical transplant, $T$, injected two weeks post injury. (A) Acetylcholinesterase staining (40X) of the ventral host/donor cortical interface. The arrows indicate the cortical interface region. (a) 100X magnification of the boxed region in (A). (B) GFAP immunocytochemistry (40X) of transplant injected two weeks post-injury. (b) GFAP staining of the boxed region in (B) at $100 X$.

receiving transplants one week post FP injury demonstrated no significant improvements in recovery when compared to controls. However, neurological motor scores of animals receiving transplants one week post injury were significantly better than the motor scores of animals receiving transplants four weeks post injury. The trends in neurological motor behavior were supported by similar trends in histological analysis data.

\section{DISCUSSION}

In the present study, FP brain injury resulted in neuronal loss within left parietal cortex, subsequent "thinning" of the cortex, and the development of a cavity lined with a glia limitans.
Unlike cortical scoop or stab injuries, the dura remains intact during FP brain injury. As a result, this experimental model may be a more clinically relevant model of concussive or traumatic brain injury. The resultant sequelae of pathological post-traumatic events include brain edema, gradual infiltration of mesodermal as well as macrophage cells, and a distinctly timed gliotic response /12/ analogous to the gliotic cavitation reported in spinal cord traumatic models /48/. Although reactive gliosis has previously been reported to occur within one hour following FP injury /12/, a complete gliallined cavity does not develop until more than two weeks post injury. This observation is similar to the time course of astrocytic scarring reported for spinal cord $/ 28 /$. 

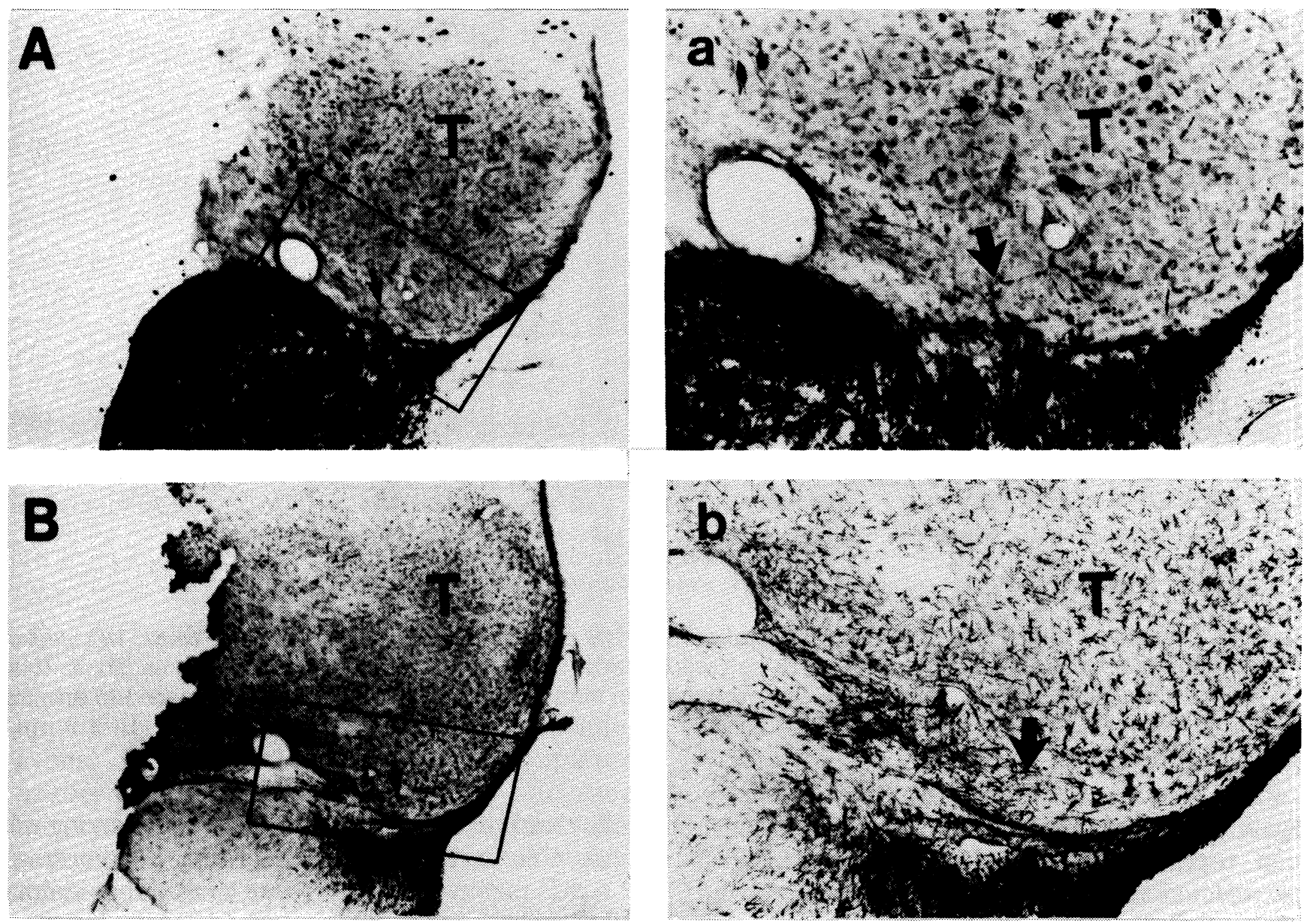

Fig. 5: E16 fetal cortical transplant, T, injected four weeks post-injury. (A) Acetylcholinesterase staining (40X) of the ventral host/donor cortical interface. The arrows indicate the cortical interface region. (a) $100 \mathrm{X}$ magnification of the boxed region in (A). (B) GFAP immunocytochemistry (40X) of transplant injected four weeks post injury. (b) GFAP staining of the boxed region in (B) at 100X.

Fetal tissue transplanted four weeks post injury often became separated from host tissue by a pronounced glial scar and rarely exhibited AchE-positive fibers traversing host/donor cortical interfaces. It is conceivable that the glial "scar" physically impeded passage of fibers between the transplant and host brain. The concept of a gliotic physical barrier to axonal outgrowth has been forwarded by a number of investigators 14,34,49,64/. Mechanisms controlling reactive gliosis and complete scar formation in adults remain unclear. Interestingly, glial scars do not readily form in newborns $/ 3 /$ perhaps due to the immature nature of their astrocytes. The lack of glial scarring in newborns may also account for the greater success of transplant survival in newborns than in adults. In addition to the physical barrier imposed by the glial scar, inhibition of axonal outgrowth may also be affected by inhibitor growth proteins found within mature astrocytes $/ 5 /$ and oligo-dendrocytes $/ 8,11,16,52 /$. Alternatively, astrocytes may inhibit regeneration by activating a physiological stop pathway similar to the one utilized during the developmental formation of terminals on target cells $/ 37 /$.

Fetal cortical tissue transplanted four weeks post injury also exhibited reactive gliosis throughout the entire transplant and especially along host/donor interfaces. Nissl staining of fetal cortical transplants injected four weeks post injury showed numerous infiltrations of macrophage cells. Although the brain is generally believed to be an immunologically privileged 


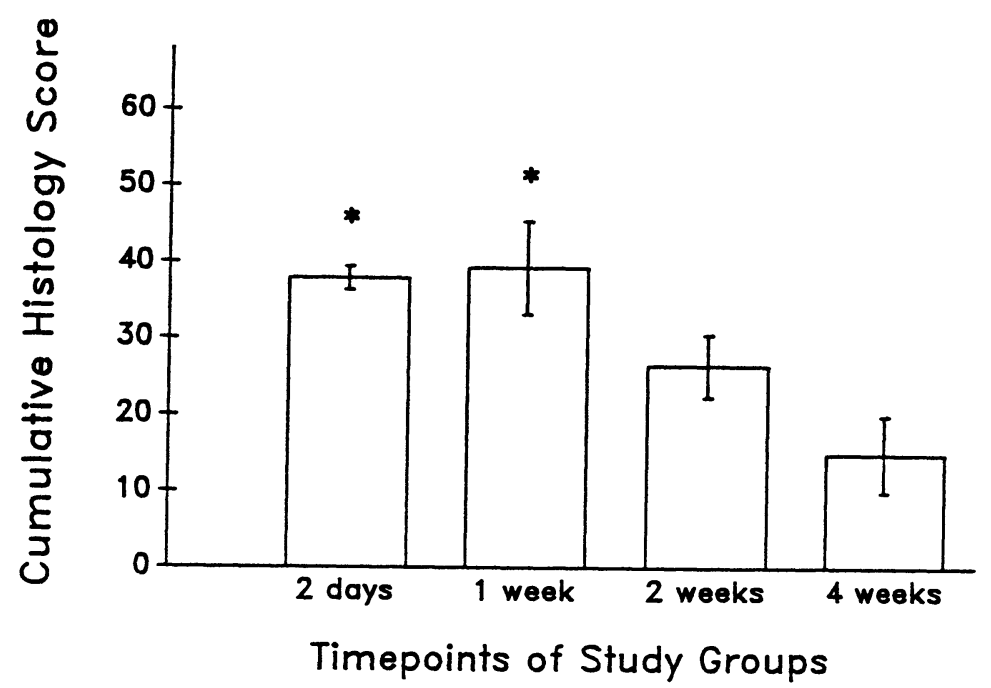

Fig. 6: Cumulative histological score of E16 fetal cortical transplants injected two days, one week, two weeks, and four weeks post injury. All analyses were made four weeks following transplant injections. Total possible cumulative score was 68 . Data graphed as means \pm SEM. ${ }^{*} p<0.05$ when compared to animals receiving transplants four weeks post injury.

organ, rejections of fetal CNS transplants have been reported $/ 2,32,38,39 /$. Transplants which are rejected first experience an increase in the number of GFAP positive astrocytes, both in and around the transplant, followed by a focused destruction of donor astrocytes /39/. Expression of class I and II MHC antigens within the transplant has also been documented $/ 32,38,39 /$. Precisely which CNS cell type participates in the presentation of $\mathrm{MHC}$ antigens remains an issue currently under debate $/ 2,40 /$. Astrocytes have been induced to express MHC antigens by immunologic signals such as gamma interferon /63/, and peripheral nerve lesions can induce MHC I expression on the afferent motor neurons $/ 40 \%$. However, it is unclear whether reactive astrocytes present in the fetal cortical transplants injected four weeks post injury signal impending immunological rejection of these transplants. Clearly, elucidation of the immunological mechanisms associated with fetal CNS transplantation is an important area for future research.

In the present study, transplants injected 2 days, 1 week, and 2 weeks post injury survived and were incorporated into the host tissue. There was little evidence of a glial scar at the two day and one week time points. Glial scarring was variable in the two week group. Furthermore, AchE-positive fibers were numerous along host/donor interfaces and GFAP immunoreactivity was scarce throughout these transplants as well as along host/donor interfaces. A similar pattern of robust fiber exchange concurrent with scarce GFAP immunoreactivity has been noted in both spinal cord /28/ as well as in optic nerve transplantation studies 127/. It has been suggested that CNS grafts transplanted into acute lesions attenuate the glial scarring reaction $/ 28,33,34,48,49 /$ although the mechanisms remain obscure. Donor astrocytes have been reported to migrate from the transplant into host tissue apparently following either the basal lamina or parallel bundles of nerve fibers $/ 21,36 /$. It appears possible that a morphological as well as a physiological difference exists between "immature" donor astrocytes and reactive "mature" host astrocytes. Immature astrocytes appear morphologically different in culture, and have distinct radial aggregational features on nitrocellulose filters implanted in vivo than mature astrocytes which develop thick tubular processes and aggregate randomly $/ 51 /$. In addition, immature astrocytes 
TABLE 1. COMPOSITE NEUROSCORES OF TRANSPLANT VS. CONTROL.

\section{TIMEPOINTS}

\begin{tabular}{|c|c|c|c|}
\hline GROUPS & 1 Week & 2 Weeks & 4 Weeks \\
\hline Transplants & $16^{*}(n=10)$ & $12(n=11)$ & $11.75(n=8)$ \\
\hline Controls & $15 \quad(n=8)$ & $15(n=9)$ & $14.50(n=8)$ \\
\hline \multicolumn{4}{|c|}{${ }^{*} \mathrm{p}<0.05$ when compared to four-week transplant animals. } \\
\hline \multicolumn{4}{|c|}{$\begin{array}{l}\text { Composite neurological indices included vertical, left, and right angle-board; right forelimb contraflexion; } \\
\text { and right lateral pulsion. Each score is ranked on a scale of } 0-4 \text {, with } 4 \text { being the best. Total possible }\end{array}$} \\
\hline
\end{tabular}

apparently support outgrowth of commissural axons in acallosal animals while mature astrocytes do not /58/. Perhaps immature astrocytes act in some fashion to inhibit glial scarring by mature reactive astrocytes within injured host brain.

There have been reports demonstrating behavioral improvements when replacing lost cortex populations with fetal cortical tissue $135,59,60 /$. However, the cortex organizes a wide variety of complex behavior. In lateral FP brain injury, parietal/temporal and occipital cortex neuronal populations are lost. Not only are cortical neurons lost, but hippocampal and thalamic populations also degenerate. As a result, FP injured rats exhibit profound motor dysfunction as well as learning and memory deficits. In this study, the motor scores of FP injured animals receiving fetal cortical tissue into lesioned motor cortex did not significantly differ from control motor scores at any of the time points examined. However, the trends between the groups were different. Animals receiving transplants four weeks post injury tended to perform worse than controls whereas animals receiving transplants one week post injury tended to perform better than controls. The two week neurological scores were quite varied. These trends were reflected in the histological analysis of the transplants.
Motor behavior involves complex neuronal circuitry and any effects by the transplants may have been too subtle to discern with the particular motor outcome measures utilized in this study. Alternatively, the inability of the transplants to significantly attenuate motor deficits may indicate inappropriate host/ transplant interactions. Curiously, animals receiving transplants four weeks post injury exhibited significantly higher activity monitor scores when compared to the four week control group. A similar hyperactivity was noted in animals whose transplants were placed in frontoparietal cortex after suction lesions /31/. Perhaps this hyperactivity may signify abnormal transplant function. Further neurological behavioral tests (i.e. learning and memory) need to be examined before a definitive conclusion concerning the effectiveness of cortical transplants in concussive brain injury can be drawn.

\section{CONCLUSIONS}

Our results suggest that a temporal window exists for successful transplant survival in experimental head injury. Perhaps there exists a critical time point in which neuronal populations can be saved. Whether spared neuronal popula- 
tions retain normal function remains to be demonstrated. Transplants injected prior to four weeks post FP injury will attenuate glial scarring resulting from the concussive trauma. Unfortunately, once the scar forms, fetal cortex transplants have little effect upon scar attenuation. The scar's physical presence possibly further inhibits transplant incorporation with host tissue leading to subsequent immunological rejection. Nonetheless, fetal grafts may still provide necessary neurotrophic factors required for neuronal survival of adjacent systems. While fetal transplantation may not be the ultimate answer for post-traumatic neuronal loss and degeneration, it will certainly provide important insights towards an understanding of the regenerative processes involved in traumatic brain injury.

\section{ACKNOWLEDGEMENTS}

This work was supported, in part, by an NIH Grant (NS26818), a grant from the Sunny von Bulow Coma and Head Injury Foundation, and a NIDCD Training Grant (T32 DC0002504NIDCD). Special thanks go to Drs. Manuel Gonzalez and Frank Sharp for valuable discussions. We gratefully acknowledge Dr. Richard St. Marie for his constructive comments on the manuscript and Joanne D'Aprile for its preparation. This work was completed, in part, towards the fulfillment of doctoral degree requirements at the University of Connecticut Health Center. In these studies, we carefully adhered to the animal welfare guidelines set forth in the Guide for the Care and Use of Laboratory Animals, U.S. Department of Health and Human Services, Pub. No. 85-23, 1985.

\section{REFERENCES}

1. Adams JH, Mitchell DE, Graham DI, Doyle D. Diffuse brain injury of immediate impact type. Brain 1977; 100: 489-502.

2. Bartlett PF, Kerr RSC, Bailey A. Expression of MHC antigens in the central nervous system. Trans Proc 1989; 21(1): 3163-3165.

3. Berg DK. New neuronal growth factors. Ann Rev Neurosci 1984; 7: 149-170.
4. Berry M, Maxwell WL, Logan A, Mathewson A, McConnell P, Ashhurst DE, Thomas GH. Deposition of scar tissue in the central nervous system. Acta Neurochirurgica (Suppl) 1983; 32: 31-53.

5. Bignami A, Dahl D, Gilad VH, Gilad GM. Hyaluronate-binding protein produced by white matter astrocytes: An axonal growth repellent? Exp Neurol 1988; 100: 253-256.

6. Bjorklund A, Stenivi U. Intracerebral neural implants: Neuronal replacement and reconstruction of damaged circuitries. Ann Rev Neurosci 1984; 7: 279-308.

7. Bregman BS, Reier PJ. Neural tissue transplants rescue axotomized rubrospinal cells from retrograde death. J Comp Neurol 1986; 244: 86-95.

8. Caroni P, Schwab ME. Antibody against myelinassociated inhibitor of neurite growth neutralizes nonpermissive substrate properties of CNS white matter. Neuron 1988; 1: 85-96.

9. Castro AJ, Zimmer J, Sunde NA, Bold EL. Transplantation of fetal cortex to the brain of newborn rats: A retrograde fluorescent analysis of callosal and thalamic projections from transplant to host. Neurosci Lett 1985; 60: 283-288.

10. Chang FLF, Steedman JG, Lund RD. The lamination and connectivity of embryonic cerebral cortex transplanted into newborn rat cortex. J Comp Neurol 1986; 244: 401-411.

11. Chiquet $M$. Neurite outgrowth by CNS myelin proteins: A mechanism to confine fiber tracts? TINS 1989; 12(1): 1-3.

12. Cortez S, McIntosh TK, Noble L. Experimental fluidpercussion brain injury: Vascular disruption and neuronal and glial alterations. Brain Res 1989; 482(2): 271-282.

13. Denny-Brown D, Russel WR. Experimental cerebral concussion. Brain 1941; 64: 93-164.

14. Dixon CED, Lyeth BG, Povlishock JT, Findling RL, Hamm RJ, Marmarou A, Young HF, Hayes RL. A fluid-percussion model of experimental brain injury in the rat. J Neurosurg 1987; 67: 110-119.

15. Ebner F, Erzurmlu RS, Lee SM. Peripheral nerve damage facilitates functional innervation of brain grafts in adult sensory cortex. Proc Natl Acad Sci 1989; 86: 730-734.

16. Fawcett JW, Rokos J, Kadst I. Oligodendrocytes repel axons and cause axonal growth collapse. J Cell Biol 1989; 92: 93-100.

17. Floeter MK, Jones EJ. Connections made by transplants to the cerebral cortex of rat brains damaged in utero. J Neurosci 1984; 4(1): 141-150.

18. Floeter MK, Jones E.J. Transplantation of fetal postmitotic neurons to rat cortex: Survival, early pathway choices and long-term projections of outgrowing axons. Dev Brain Res 1985; 22: 19-38.

19. Freed WJ, Connon-Spoor HE. Cortical lesions increase reinnervation of the dorsal striatum by 
substantia nigra grafts. Brain Res 1988; 446: 133-143.

20. Gennarelli TA, Seqawa H, Walde U. Physiological response to angular acceleration of the head. In: Grossman PG, Gildengers PL, eds., Head Injury: Basic and Clinical Aspects. New York: Raven Press, 1982; 129-140.

21. Goldberg WJ, Bernstein JJ. Fetal cortical astrocytes migrate from cortical homografts throughout the host brain and over the glia limitans. J Neurosci Res 1988; 20: 38-45.

22. Gonzalez MF, Sharp FR. Fetal frontal cortex transplanted to injured motor/sensory cortex of adult rats. I. NADPH-diaphorase neurons. J Neurosci 1987; 7(10): 2991-3001.

23. Gonzalez MF, Sharp FR, Loken JE. Fetal frontal cortex transplanted to injured motor/sensory cortex of adult rats: Reciprocal connections with host thalamus demonstrated with WGA-HRP. Exp Neurol 1988; 99: 154-165.

24. Harvey AR, Gan SK, Pauken JM. Fetal tectal or cortical tissue transplanted into brachial lesion cavities in rats: Influence on the regrowth of host retinal axons. J Comp Neurol 1987; 263: 126-136.

25. Haun F, Cunningham TJ. Cortical transplants reveal CNS trophic interactions in situ. Dev Brain Res 1984; 15: 290-294.

26. Haun F, Cunningham TJ. Specific neurotrophic interactions between cortical and subcortical visual structures in developing rat: in vivo studies. J Comp Neurol 1987; 256: 561-569.

27. Hausmann B, Siever J, Hermanns J, Berry $M$. Regeneration of axons from the adult rat optic nerve: Influence of fetal brain grafts, laminin, and artificial basement membrane. J Comp Neurol 1989; 281: 281466.

28. Houle JD, Reier PJ. Transplantation of fetal spinal cord tissue into the chronically injured adult rat spinal cord. J Comp Neurol 1988; 269: 535-547.

29. Jaeger $\mathrm{CB}$, Lund $\mathrm{RD}$. Efferent fibers from transplanted cerebral cortex of rats. Brain Res 1979; 165: 338-342.

30. Jare JA, Rinel RW, Pobereskyn LH, Tysor GW, Steward O, Gennarelli T. Outcome and pathology of head injury. In: Grossman GR, Gilden PL, eds, Head Injury: Basic and Clinical Aspects. New York: Raven Press, 1982.

31. Justice A, Moran TH, Deckel AW, Robinson RG. The use of fetal neocortical transplants to treat hyperactivity resulting from cortical suction lesions in adult rats. Behav Brain Res 1989; 33(1): 97-104.

32. Kerr RSC, Bartlett PF. The immune response to intraparenchymal fetal CNS transplants. Transplant Proc 1989; 21(1): 3166-3168.

33. Kromer LF. Glial scar formation in the brain of adult rats is inhibited by implants of embryonic CNS tissue. Soc Neurosci Abstr 1980; 6: 688.

34. Kruger S, Sievers J, Hansen C, Sadler M, Berry M.
Three morphologically distinct types of interface develop between adult host and fetal brain transplants: Implications for scar formation in the adult central system. J Comp Neurol 1986; 249: 103116.

35. Labbe R, Firl A, Mufson EJ, Stein DG. Fetal brain transplants: Reduction of cognitive deficits in rats with frontal cortex lesions. Science 1983; 221: 470-472.

36. Lindsay RM, Raismann G. An autoradiographic study of neuronal development, vascularization and glial cell migration from hippocampal transplants labeled in intermediate explant culture. Neuroscience 1984; 112: 513-530.

37. Liuzzi FJ, Lasek RJ. Astrocytes block axonal regeneration in mammals by activating the physiological stop pathway. Science 1987; 237: 642645.

38. Lund RD, Kunz HW, Gill TJ. Neural transplantation and the immune response. In: Goetzl EJ, Spector NH, eds, Neuroimmune. Networks: Physiology and Diseases. New York: Alan R. Liss, 1989; 269-278.

39. Lund RD, Houston MB, Lagenaur CF, Kunz HW, Gill TJ. Cellular events associated with induced rejection of neural xenografts placed into neonatal rat brains. Transplant Proc 1989; 21(1): 3174-3175.

40. Maehlen J, Nennesons I, Olsson AB, Daa A, Schrodor $H$, Kristensson $K$. Peripheral nerve injury causes transient expression MHC I antigens in rat motor neurons and skeletal muscle. Brain Res 1989; 481(2): 368-372.

41. Manthorpe M, Nieto-Sampedro M, Skaper SD, Lewis EG, Barbin G, Longo FM, Cotman CW, Varon S. Neuronotrophic activity in brain wounds of the developing rat. Correlation with implant survival in the wound cavity. Brain Res 1983; 267: 47-56.

42. McIntosh TK, Vink R, Noble L, Yamakami I, Soares $H$, Faden A. Traumatic brain injury in the rat: Characterization of a lateral fluid-percussion model. Neuroscience 1989; 28: 233-244.

43. Nieto-Sampedro $M$, Whittemore SR, Needels DL, Larson J, Cotman CW. The survival of brain transplant is enhanced by extracts from injured brain. Proc Natl Acad Sci 1984; 81: 6250-6254.

44. Nieto-Sampedro M, Manthrope M, Barbin G, Varon $S$, Cotman CW. Injury-induced neuronotrophic activity in adult rat brain: Correlation with survival of delayed implants in the wound cavity. J Neurosci 1983; 3(11): 2219-2229.

45. Nieto-Sampedro M, Lewis ER, Cotman CW. Brain injury causes a time-dependent increase in neuronotrophic activity at the lesion site. Science 1982; 271: 860-861.

46. Paxinos G, Watson C. The Rat Brain in Stereotaxic Coordinates. New York: Academic Press, 1986.

47. Povlishock J. The morphopathologic responses to experimental head injury of varying severity. In: Povlishock JT, Becker DP, eds, CNS Trauma Status 
Report. Washington, D.C.: William Byrd Press, 1986; 443-452.

48. Reier PJ, Stensass LJ, Guth L. The astrocytic scar as an impediment to regeneration in the central nervous system. In: Kaoj CC, Bunge RP, Reier PJ, eds, Spinal Cord Reconstruction. New York: Raven Press, 1983; 163-195.

49. Reier PJ, Bregman BS, Wujek JR. Intraspinal transplantation of embryonic spinal cord tissue in neonatal and adult rats. J Comp Neurol 1986; 247: 274-296.

50. Rinder L, Olsson Y. Studies on vascular permeability changes in experimental brain concussion. Acta Neuropathol 1968; 11: 183-188.

51. Rudge JS, Smith GM, Silver J. An in vitro model of wound healing in the CNS: Analysis of cell reaction and interaction at different ages. Exp Neurol 1989; 103: 1-16.

52. Schwartz M, Cohen A, Stein IC, Belkin M. Dichotomy of glial cell response to axonal injury and regeneration. FASEB J 1989; 3(12): 2371-2378.

53. Sharp FR, Gonzalez MF. Fetal frontal cortex transplant $\left({ }^{14} \mathrm{C}\right)$ 2-deoxyglucose uptake and histology: Survival in cavities of host rat brain motor cortex. Neurology 1984; 34: 1305-1311.

54. Sharp FR, Gonzalez MF, Ferriero D, Sagar SM. Injured adult neocortical neurons sprout fibers into surviving fetal frontal cortex transplants: Evidence using NADPH-Diaphorase staianing. Neurosci Lett 1986: 65: 204-208.

55. Sharp FR, Gonzalez MF. Fetal cortical transplants ameliorate thalamic atrophy ipsilateral to neonatal frontal cortex lesions. Neurosci Lett 1986; 71: 247251.

56. Sharp FR, Gonzalez MF, Sagar SM. Fetal frontal cortex transplanted to injured motor/sensory cortex of adult rats. II. VIP-, somatostatin, and NPYimmunoreactive neurons. J Neurosci 1987; 7(10): 3002-3015.
57. Sievers J, Hausmann B, Berry M. Fetal brain grafts rescue adult retinal ganglion cells from axotomyinduced cell death. J Comp Neurol 1989; 281: 467-478.

58. Smith SG, Miller RH, Silver J. Changing role of forebrain astrocytes during development, regenerative failure, and induced regeneration upon transplantation. J Comp Neurol 1986; 251: 23-43.

59. Stein DG, Labbe R, Attella MJ, Rakowsky HA. Fetal brain tissue transplants reduce visual deficits in adult rats with bilateral lesion of the occipital cortex. Behav Neural Biol 1985; 44: 266-277.

60. Stein DG, Palatucci C, Kahn D, Labbe R. Temporal factors influence recovery of function after embryonic brain tissue transplants in adult rats with frontal cortex lesions. Behav Neurosci 1988; 102(2): 260-267.

61. Tago H, Kimura H, Maeda T. Visualization of detailed acetylcholinesterase fiber and neuron staining in rat brain by a sensitive histochemical procedure. $\mathrm{J}$ Histochem Cytochem 1986; 34(11): 1431-1438.

62. Tornheim PA. Traumatic edema in head injury. In: Povlishock JT, Becker DP, eds, CNS Trauma Status Report. Washington, DC: William Byrd Press, 1986.

63. Wong GHW, Bartlett G, Clark-Lewis I, Battye I, Schrader JW. Inducible expression of $\mathrm{H}-2$ and Ia antigens on brain cells. Nature $1984 ; 310$ : 688-691.

64. Wujek JR, Reier PR. Astrocytic membrane morphology: Differences between mammalian and amphibian astrocyte after axotomy. J Comp Neurol 1984; 222: 607-619.

65. Yamakami I, McIntosh TK. Effects of traumatic brain injury on regional cerebral blood flow in rats as measured with radiolabeled microspheres. J Cereb Blood Flow Metab 1989; 9: 117-124.

66. Young W. The post injury responses in trauma and ischemia. Secondary injury or protective mechanisms? CNS Trauma 1987; 4: 27-51. 

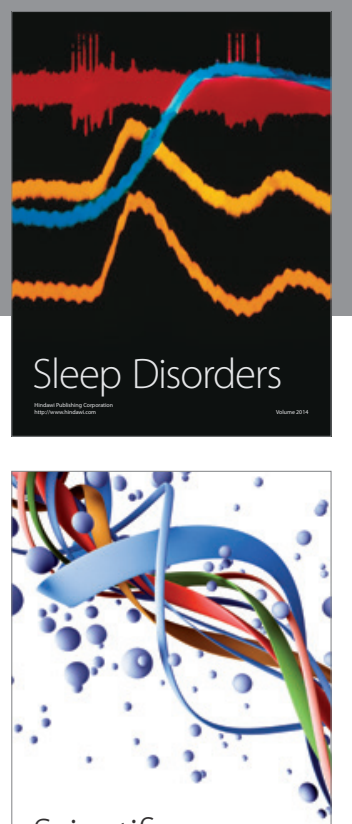

Scientifica
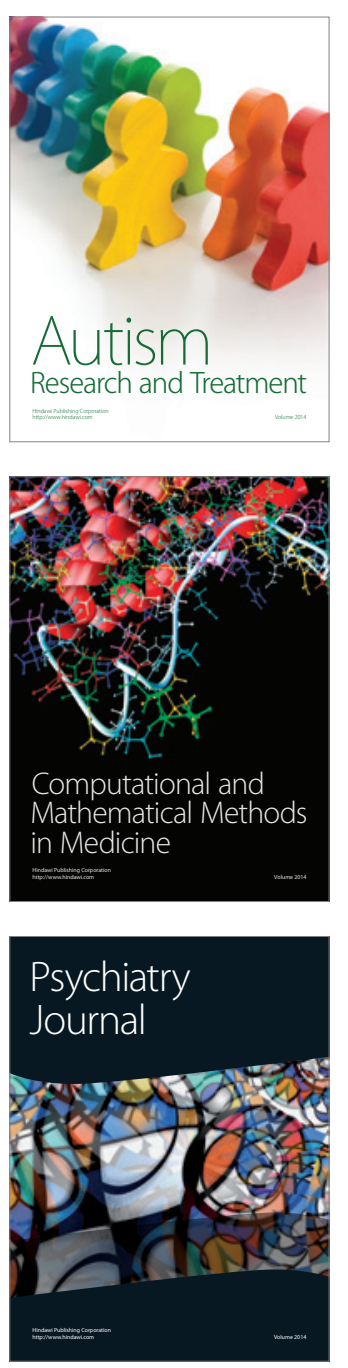
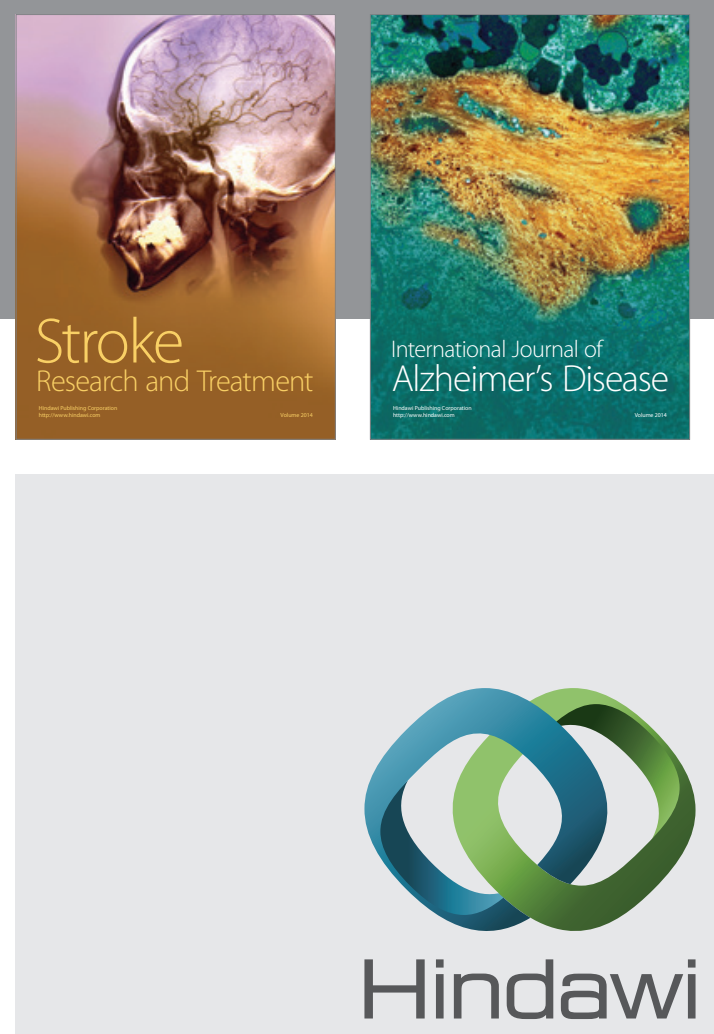

Submit your manuscripts at

http://www.hindawi.com
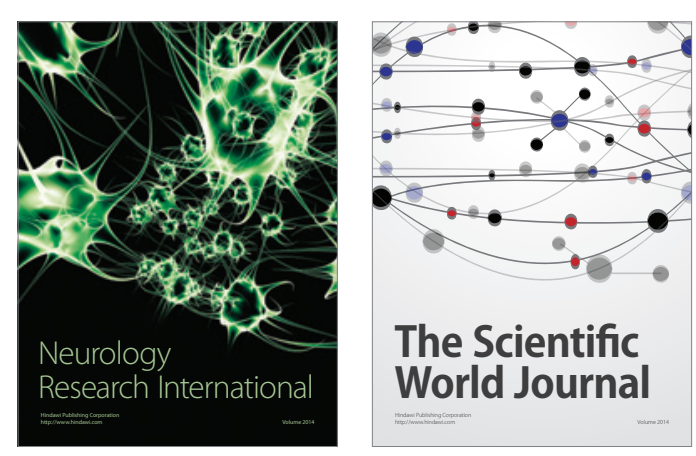

The Scientific World Journal

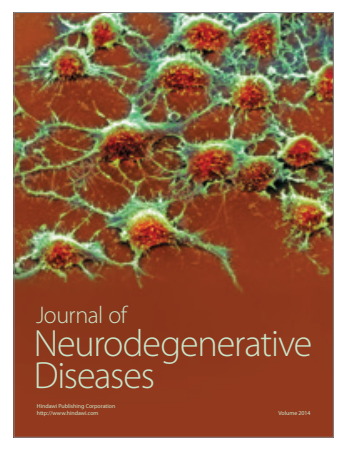

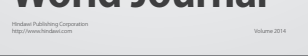

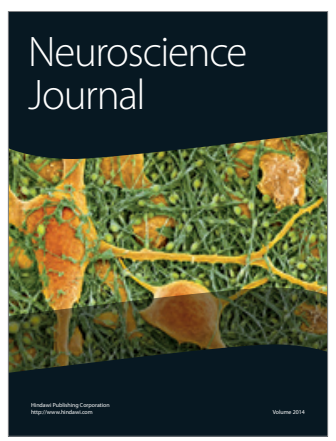

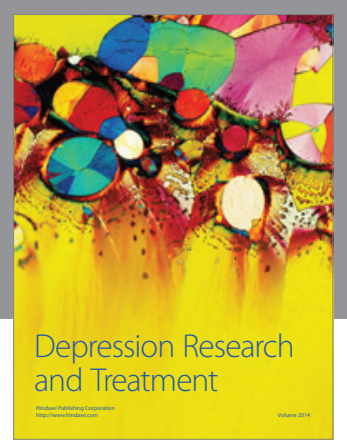
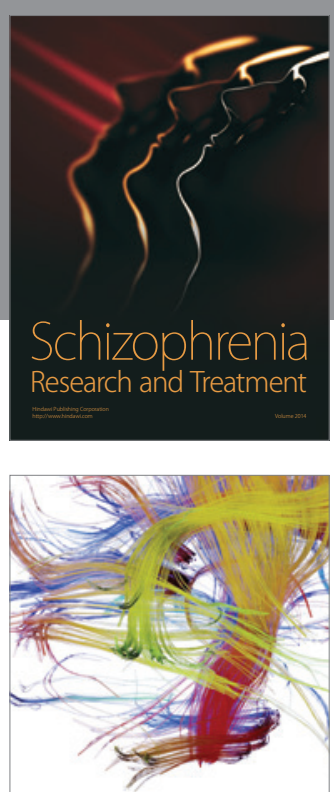

Brain Science

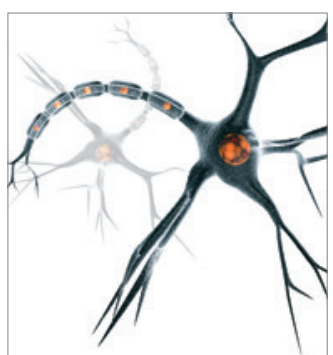

Neural Plasticity
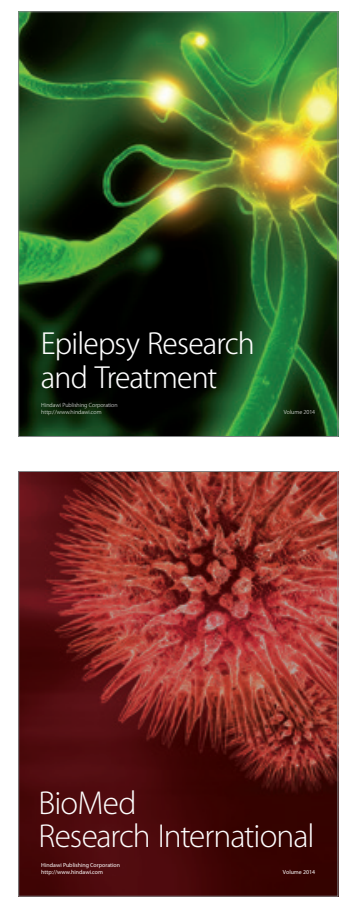

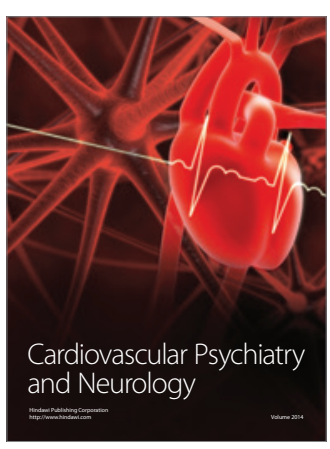

Parkinson's

Disease
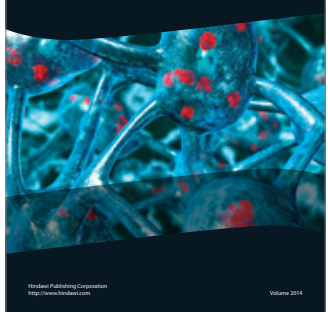